\title{
The Incorporation of Biomimicry into an Architectural Design Process: A New Approach towards Sustainability of Built Environment
}

\author{
Parag L. Sarwate and Akshay P. Patil
}

\begin{abstract}
A brief literature review on Biomimicry and Architecture has been arranged into a rational system and has been systematically customized to find the application of Biomimicry in the design processes involved architecture. The main objective of this research is to find out how Biomimicry principles help in architecture of space, structure or enclosure, its experience in space \& time, technological achievement, program or strategy development and compatibility to its context. Mapping of research literature has been done on the basis of a framework of the System of Inquiry, Strategies and Tactics.
\end{abstract}

Keywords--- Biomimicry, Architectural Systems, Process Design, Sustainable Built Environment

\section{INTRODUCTION}

$\mathrm{T}$ HE concept of biomimicry talks about the ideas inspire from nature and transfers those to create sustainable design solutions. This concept is considered as one of the most promising solution for sustainable development. Biomimicry differs from other nature friendly or green concepts. Animals, plants and microbes are skilled engineers. They have found what works, what is appropriate and most importantly, what lasts here on Earth [1]. Mimicry of living organisms and ecosystems to create sustainable design solutions is called biomimicry.

The term biomimicry is invented by author J. Benysus in her book [1]. She mentioned various ecological examples and works, nature's laws, strategies, principles etc in her research. Her findings have shown that during its 3.8 billion years of research and development, nature has evolved highly efficient systems and processes that can inform [1] architectural design problems we face today; she says in fact, nature has already achieved what we are still trying to do, without causing a detrimental effect on the planet. So the underlying idea of biomimicry is that we can use the forms, processes and systems found in nature to inform efficient, sustainable and environmentally sensitive architecture [1]. Biomimicry becomes a source of inspiration to solve various design problems. It is the new medium with wide range of options to create a sustainable world in true sense. This science and philosophy of learning from nature, the concept of biomimicry

Parag L. Sarwate, M. Arch Research Scholar, Department of Architecture and Planning, Vishveshvaraya Institute of Technology, Nagpur-440010, India. E-mail:arparags@gmail.com

Akshay P. Patil, Associate Professor, Department of Architecture and Planning, Vishveshvaraya Institute of Technology, Nagpur - 440010, India. E-mail:akshayppatil@gmail.com DOI: 10.9756/BIJIEMS.10443 is a source of architectural design inspiration, with a variety of approaches undertaken by designers that reference nature.

This paper examines research literature on Biomimicry principles in design of spaces/structures/enclosures based on technological advancements, to accommodate a program and these three systems compatible to its context. It includes a comparative analysis of available literatures to understand the application of biomimicry in architecture.

It is assumed that application of biomimicry to the architectural design becomes a platform to create a sustainable built environment [2]. This is an effort to explore recent research developments of the application of biomimicry principles in process design, object design and realization design [3] which are the inherent part of architectural design.

Literature review revealed Biomimicry principles evolve as an improved sustainable model in architectural design. These biomimicry principles can be explored to improve the sustainability of architectural design. This paper also explores the literature on architectural systems and process design for better insight. This paper is an effort to review the literature and elucidate the application of biomimicry in architectural system and process design. Research papers on Biomimicry have been studied under the framework of System of Inquiry, Strategies and Tactics. The methodology followed in this review is summarized in figure1. This methodology is adopted from Linda Groat and David Wang's book titled 'Architectural Research Methods' [4].

Research papers have been studied to understand the term biomimicry and its application on various design fields. This literature review will be helpful to scholars and researchers in the field of Biomimicry and Architecture. The literature review is a part and parcel of the research. It is essential not only at the beginning of the process, but throughout research [4].

\section{CORRELATING BIOMIMICRY WITH ARCHITECTURE AND PROCESS DESIGN}

The concept of Biomimicry can be summarized as the inspiration from nature's processes \& ecosystems, which would provide useful parameters to design societies and complexes [5]. Biomimicry offers an innovative and nature friendly approach which can create more adaptive and flexible solutions [6]. Theories in Biomimicry feature similarities between biological and social complex systems that can provide guidance in the management of several issues, the design process and collective intelligence. Bottom up 
approach theories in Biomimicry include, self organization, optimize rather than maximize, use free energy, crosspollinate, embrace diversity, adapt and evolve, use lifefriendly materials and processes, engage in symbiotic relationships, and enhance the bio-sphere [7]. The applications of these theories have been majorly done in industrial products till date. However, so far its application in architecture and its allied design processes often shows its limited and unexplored use.

\section{A. Application of Biomimicry}

Approach to biomimicry as a design process can broadly be distinguished in two categories [2]:

1. Defining design problem and then identifying \& mimicking the ecosystem of other organisms to that design problem [8].

2. Looking to biological systems or processes and identifying a particular characteristic or behaviour or function in an organism or system and translating that to human designs. [8].

Within these two approaches application of biomimicry to the architectural design can be categorized under three levels, viz, form, process \& function [8]. In analyzing an organism or ecosystem, form and process are the key components that could be mimicked [2].

These three levels are termed as organism level, behaviour level and ecosystem level [2]. The organism refers to a specific living thing like a plant or an animal and it may involve mimicking a part or the whole organism. The behaviour level may relate to behaviour of living organism like how an organism behaves or relates to a larger context. The third level allows us mimicking the whole ecosystem having common principles that allow them to successfully function [2]. Application of these levels depends upon the context or design programme.

Further, five possible dimensions to mimicry exist within each of these levels [2]. The design may be in terms of what the form is, which material is used to make it, how it is constructed, how it works like process or what kind of function, it is able to do.

\section{B. Architectural Systems}

The Architectural system is summarized by D. K. Ching in his book [9]. In that it is stated that Architecture as space and form experiences through movement in time, which is achieved by means of technology. It accommodates a program and is compatible to the context.

The architecture of space/form/enclosure is the product of organizational pattern, hierarchy and relationship with the surrounding. It also has a defined image, shape, scale and proportion, the quality of colour and texture. These defined parameters of architecture are experienced through movement in space and time [9]. The 'Experience ' of approach, space, volume, light, colour, touch, etc. gives a clear image of the built environment. But to achieve this 'Experience ' of built environment, certain technology has to be adopted which benefits to create environmental protected, comfortable and durable structure.
To achieve such structure a program has to be adopted with respect to space and user which inhabits the parameters such as needs, requirements and aspirations of the user, legal restrains historical traditions and cultural characteristics of the place. As well as this program should be compatible with the geographical conditions, the ' context ' of the structure like a site - surrounding environment, climatic conditions (the sun, wind, temperature, etc.), soil, topography, vegetation, water, etc.

\section{Object Design, Realization Design, Process Design [3]}

In any design, it is necessary to plan design processes [3]. However, in most of the cases, one tends to use conventional approaches to process design. But for better and professional approach to create object design and realization design, it is necessary to design "the design process" [3].

The design processes gives both descriptive and perspective process designs as explained in literature [3]. Figure 2 shows the process design outcome from the immaterial world of designing to the material world of realizing [3].

This paper tries to relate the three major concepts and theories, application of biomimicry, system of architecture and process design theory with each other. Figure 1 shows the correlation between biomimicry, architecture and process design.

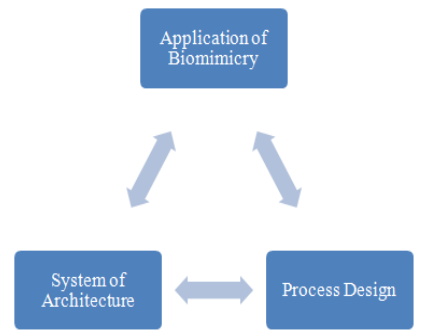

Figure 1: Correlation between Biomimicry, Architecture and Process Design

As discussed earlier, it is important to design 'the design process' to achieve sustainability in the built environment. By relating architecture to object design and by adopting biomimicry as a realization design, one can derive a process design which further can produce a sustainable outcome [3]. Relating biomimicry and architecture in the immaterial world of designing would be able to produce a realization process in the material world of realization. The literature on Biomimicry in architectural system and process design can be summarized in diagrammatic form as shown in figure 2 .

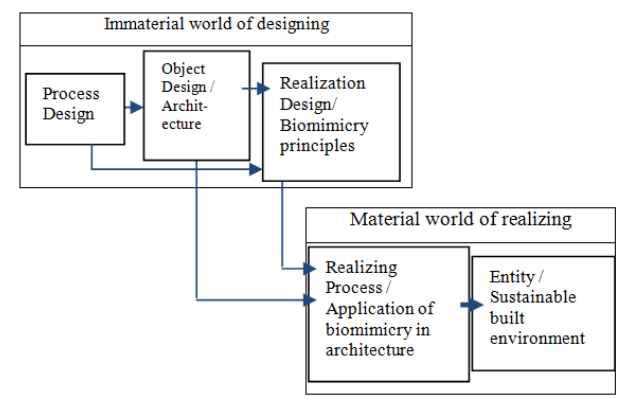

Figure 2: Relating Biomimicry with Architectural System and Process Design 


\section{LITERATURE REVIEW}

There are many research papers published on Biomimicry elucidating the epistemological and ontological grounds for multi-disciplines. Therefore the literature on Biomimicry has fluid boundaries; its scope depends upon the topic of inquiry. As detailed out in the introductory section this paper focuses on the literature on Biomimicry and its application in design processes in the architecture discipline. This paper examines some of the published literature works to understand the term biomimicry \& its application in architectural design. The summery of the literature will help to understand out of the three levels which level of biomimicry can be applicable to architectural design more efficiently.

\section{A. Research Paper - 1}

Maibritt Pedersen Zari [2] inquires about how biomimicry approaches to architectural design help in achieving more sustainability and creating a regenerative built environment. In this, a framework is used to discuss various advantages and disadvantages in different forms of biomimicry as a design methodology. She also stated various approaches as a design process identified on the basis of literature review and examination of existing biomimetic technologies [2].

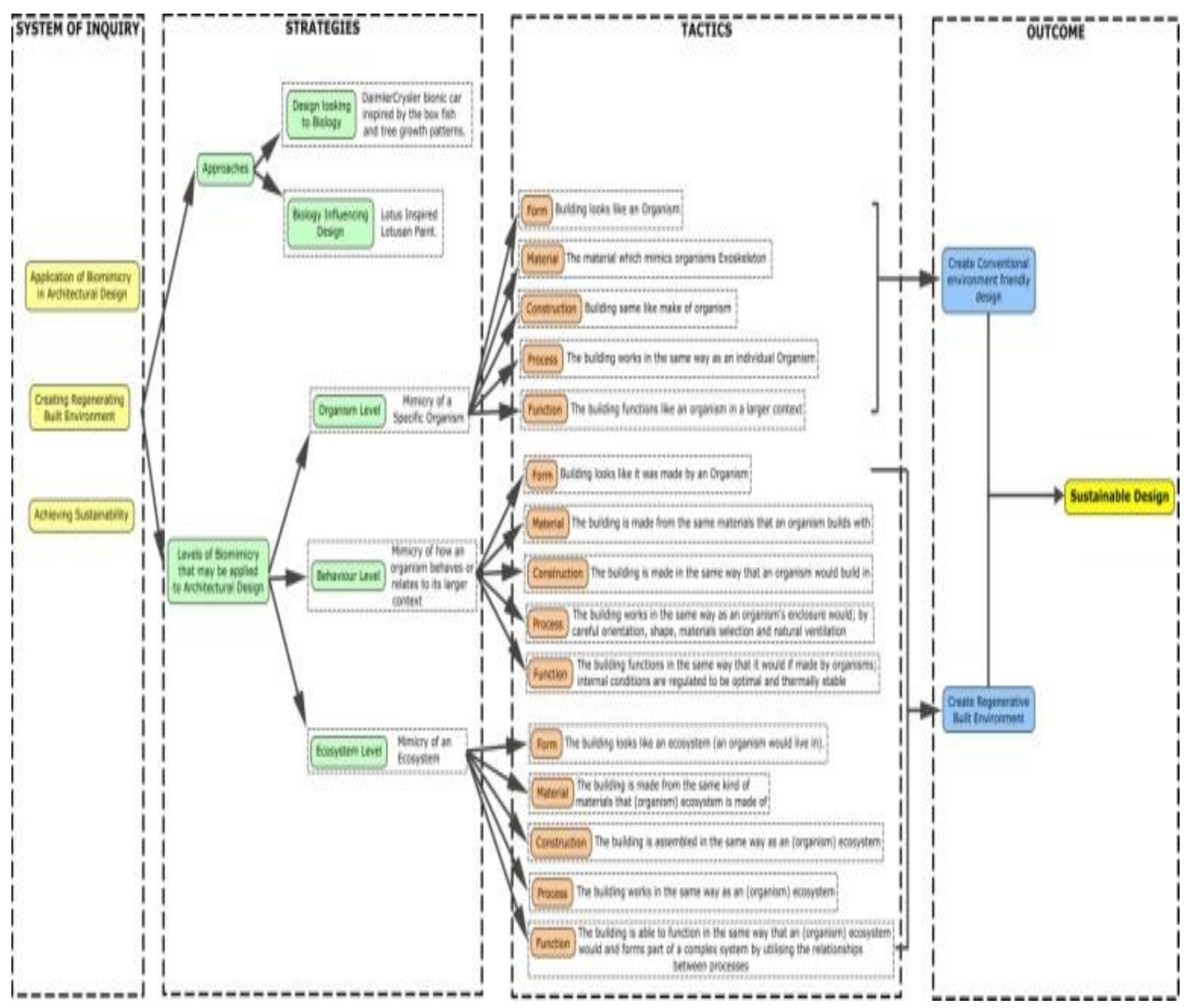

Figure 3: Mapping of Literature on the Basis of System of Inquiry, Strategies \& Tactics

Figure 3 shows how mapping of literature on Biomimicry and Architecture is done; especially it shows theoretical stance, and most importantly, its relevance for investigation [4]. Mapping of this research literature has been done on the basis of an adopted framework of the System of Inquiry, Strategies and Tactics [4]. This mapping of literature helps understand the application of Biomimicry in the design processes in the architecture discipline- the emerging research question.

\section{B. Research Paper - 2}

Maibritt Pedersen Zari [10] advocates about Biomimicry's role in addressing climate change in the built environment [10]. In this paper, certain ecosystem biomimicry principles for architecture have been studied and also explored the adaptation and mitigation techniques to address climate change. This paper concludes that the incorporation of biology and ecology into architectural design will be significant in the creation of a sustainable built environment [10]. 


\section{Research Paper - 3}

Stylianos Yiatros, M. Ahmer Wadee and Gary R. Hunt [11] inquire about how biomimicry principles can be applied in a structural design. In this, principles have been used in compression structures. The potential use of tessellation and possibility of a modular building in the micro and macro scale has checked with the help of model testing, structural analysis, fluid dynamics experiments, computer modeling.

\section{Research Paper - 4}

ELGHAWABY Mahmoud [12] tries to formulate a new concept called breathing facades. By mimicking skin properties of flora and fauna, a breathing wall concept has been developed. This helps in enhancing cooling and ventilation systems and achieving thermal comfort in buildings located in hot climate. In this paper a case of the Sinai triangular shaped Peninsula is studied.

\section{E. Research Paper - 5}

J Scott Turner and Rupert C Soar [13] seek to find how termite mounds work and application of this concept in building design. Two aspects, termite mound inspired Eastgate centre and how a termite mound is like a lung are discussed in this paper.

\section{F. Research Paper -6}

Ir A.D.C. Pronk, Monique Blacha \& Anne Bots [14] analyse mathematical patterns and structures in biology and nature in order to find its application in building technology. A possibility of use of human bone in structure is explored in this paper. Use of concrete in a building to achieve load bearing function and possibility of fiber reinforced concrete is discussed in the paper.

\section{G. Research Paper -7}

Maibritt Pedersen Zari \& J.B. Storey [15] talks about an

\begin{tabular}{|c|c|c|c|}
\hline $\begin{array}{l}\text { Research } \\
\text { Papers }\end{array}$ & Categorized Under & Study Focus & Highlights \\
\hline $\mathbf{1}$ & $\begin{array}{l}\text { Organism Level, } \\
\text { Behaviour Level, } \\
\text { Ecosystem Level }\end{array}$ & $\begin{array}{l}\text { Achieving more sustainability and creating a } \\
\text { regenerative built environment }\end{array}$ & $\begin{array}{l}\text { Framework is used to discuss various forms of biomimicry } \\
\text { as a design methodology. (Realization process) }\end{array}$ \\
\hline 2 & Ecosystem Level & $\begin{array}{l}\text { Biomimicry's role in addressing climate } \\
\text { change in the built environment [10] }\end{array}$ & $\begin{array}{l}\text { Certain ecosystem biomimicry principles for architecture } \\
\text { have been deduced [10]. (Realization process) }\end{array}$ \\
\hline 3 & Organism level & $\begin{array}{l}\text { Principles have been used in compression } \\
\text { structures }\end{array}$ & $\begin{array}{l}\text { The potential use of tessellation and possibility of a } \\
\text { modular building in the micro and macro scale } \\
\text { (Realization design, Object design) }\end{array}$ \\
\hline 4 & Organism Level & $\begin{array}{l}\text { Breathing facades, mimicking skin properties } \\
\text { of flora and fauna }\end{array}$ & $\begin{array}{l}\text { Enhancing cooling and ventilation systems and achieving } \\
\text { thermal comfort in the buildings (Realization design, } \\
\text { Object design) }\end{array}$ \\
\hline 5 & Organism Level & $\begin{array}{l}\text { How termite mounds work and application of } \\
\text { this concept in building design }\end{array}$ & $\begin{array}{l}\text { A termite mound is a lung (Realization design, Object } \\
\text { design) }\end{array}$ \\
\hline 6 & Organism Level & $\begin{array}{l}\text { Analyses mathematical patterns and structures } \\
\text { in biology and nature }\end{array}$ & $\begin{array}{l}\text { A possibility of use of human bone in structure. Use of } \\
\text { fiber reinforced concrete in building to achieve load } \\
\text { bearing function. (Realization design, Object design) }\end{array}$ \\
\hline 7 & Ecosystem Level & Ecosystem based design theory & A regenerative design approach (Realization process) \\
\hline 8 & Ecosystem Level & $\begin{array}{l}\text { A novel optimization technique inspired by } \\
\text { natural ecosystems [16] }\end{array}$ & $\begin{array}{l}\text { Improving effectiveness of the user base (Realization } \\
\text { design) }\end{array}$ \\
\hline 9 & Organism Level & $\begin{array}{l}\text { Concept which deals with the ability to collect } \\
\text { water, sunlight and wind }\end{array}$ & $\begin{array}{l}\text { Outcome of Living building. (Realization design, Object } \\
\text { design) }\end{array}$ \\
\hline 10 & Ecosystem Level & $\begin{array}{l}\text { An ecological replacement scheme using } \\
\text { traditional concepts of natural landform, natural } \\
\text { orientation and climatic resources. }\end{array}$ & $\begin{array}{l}\text { Ecology principles in building design. (Realization } \\
\text { process) }\end{array}$ \\
\hline
\end{tabular}

ecosystem based design theory for a regenerative environment. In this paper, ecosystem principles have been evolved to produce a regenerative design approach. Researcher concluded that ecology and ecologist play a vital role in generating an ecosystem based architectural design theory.

\section{H. Research Paper -8}

Gerard Briscoe and Philippe De Wilde [16] present a novel optimization technique inspired by Natural ecosystems. The paper talks about a digital ecosystem in computing and how it is useful in improving the effectiveness of user base.

\section{Research Paper-9}

Bob Berkebile and Jason Maclenan [17] explore a living building concept which deals with the ability to collect water, sunlight and wind. In this paper, author discussed about an industrial revolution (machine age) and the effects of industrial revolution on the environment. In paper researcher proposed some guidelines and the probable outcome of the Living building.

\section{J. Research Paper - 10}

Akubue Jideofor Anselm [18] proposes an ecological replacement scheme using traditional concepts of natural landform, natural orientation and climatic resources. The paper inquires how an ecological principle could be used in building design. Paper also states that the proper utilization of natural resources is need of the day.

A summary of the reviewed literature providing background for the application of Biomimicry theories are mapped in the last column (highlights) of the table1. The mapping of literature is done on the basis of the System of Inquiry, Strategies \& Tactics as shown in Figure 4. 
This mapping elucidates observations on the state of literature in terms of how it can be explored, to make use of it in the various design processes involved in the architecture discipline, the question and problem that have been addressed in the introductory section of this paper.

\section{CONCLUSION AND Future ENHANCEMENT}

Application of biomimicry principles in architectural designs can become a reality by exploring the practical ways of implementations. Biomimicry can be assumed as a realization design tool for an architectural design solution. It also can become a realization process for sustainable built environment.

There is a huge literature on Biomimicry and concepts therein. There is need to explore how these theories and concepts can be implemented and used in the design processes in the architecture discipline. The literature review revealed the need to understand the phenomenology behind science and design and there is a need to shift from aiming to increase prediction, control and manipulation of nature as a resource. The Biomimicry literature mapping helps in understanding how to participate appropriately and sustainably in Nature. An approach to biomimicry may become one of the most sustainable medium to create an efficient and effective built environment.

This paper highlights two sections based on various literatures. The first was the possibility of correlation between applications of biomimicry, architectural systems with process design. In most of the cases, it is found that till date application of biomimicry is explored for object design only. The realization design in biomimicry is still unexplored. The findings of literatures show that out of the three levels of application of biomimicry, only organism level is used for architectural solutions till now. Application of other two levels is still unexplored.

As explained by Linda Groat and David Wang [4], the literature review is an ongoing and never ending process and it should be carried throughout the research process to explore all possible avenues.

\section{REFERENCES}

[1] J. Benyus, "Biomimicry - Innovation Inspired by Nature", Harper Collins, New York, 1998.

[2] M.P.Zari, "Biomimetic Approaches to Architectural Design for Increased Sustainability", Sustainable building conference, Aukland, 2007.

[3] J.E.van Aken, "Valid Knowledge for the Professional Design of Large and Complex Design Processes", Elsevire.ltd (379-404), Netherland, 2005.

[4] L. Groat, D. wang, "Architectural Research Methods", John Wiley and Sons, INC, Canada, 2002.

[5] P. George, "Biomimicry-inspired Learning Theories", knowledgefederation.wiki.ifi.no, 2007.

[6] A. Marshall, S. Lozeva, "Questioning the Theory and Practice of Biomimcry, International Journal of Design and nature and Ecodynamics, 1-10, 2009.

[7] D.C.Wahl, "Bionics vs. Biomimicry: From Control of Nature to Sustainable Participation in Nature", WIT transactions on Ecology and the Environment, 289-298, 2006.

[8] www.biomimicryguild.com, 2007.

[9] Francis D.K. Ching, "Architecture: Form, Space and Order", second edition, Van Nsotrand Reinhold, 1996.
[10] M.P.Zari, "Biomimetic Design For Climate Change Adaptation and Mitigation", Architectural Science Review, 172-183, 2010.

[11] S.Yiatros, M.A.Wadee, G.R.Hunt, "The Load Bearing Duct: Biomimicry in structural design, London, 2007.

[12] E.Mahmoud, "Biomimicry: a New Approach to Enhance the Efficiency of Natural Ventilation Systems in Hot Climate", International seminar arquitectonics network, Architecture and research, Barcelona, 2010.

[13] J.S.Soar, "Beyond Biomimicry: What Termites Can Tell Us about the Living Building", 2008.

[14] Pronk, I. A., Blacha, M., \& Bolts, A., "Nature's Experiences for Building Technology, Eindhoven University of Technology postbus, Eindhoven, Netherland

[15] M. P. Zari \& Storey, J. B., "An Ecosystem Based Biomimetic Theory for a Regenerative Built Environment", Lisbon sustainable building conference, Lisbon, Portugal, 2007.

[16] G. Brisue \& P.D. Wilde, "Digital Ecosystems: Evolving Service Oriented Architectures", IEEE, 2006

[17] B. Berkebile \& J. Mclennan, "The Living Building: Biomimicry in Architecture, Integrating Technology with Nature".

[18] A. J. Anselam, "Building with Nature (Ecological Principles in Building Design)", Journal of Applied Sciences, 958-963, 2006.

[19] S. Ramaswamy, "Biomimicry: An Analysis of Contemporary Biomimetic Approches", SID Research Cell, CEPT University, India, 2011

[20] www.wikipedia.org

[21] S.P. Mead, "Biomimetics: Biologically Inspired Ideas For Construction", International Journal of Construction Education \& Research, USA, 2008.

[22] Sue L. T. McGregor, "Transdisciplinarity and Biomimicry", Transdisciplinary Journal of Engineering \& Science, The Atlas, ISSN: 1949-0569, 57-65, Vol. - 4, 2013 